\title{
Variability in L2 acquisition of formulaic sequences: A study of linguistic factors in the use and learning of phrasal verbs by non-native speakers
}

\author{
Rafael Alejo-González \\ ralejo@unex.es \\ Universidad de Extremadura, Spain
}

\begin{abstract}
In this paper, the acquisition of phrasal verbs (PVs) by L2 learners is explored from the perspective provided by a usage-based approach to language. This involves looking at low scope or item-specific schemas, which in this article are identified as the actual particles, prepositions and PVs used by the learners, together with the more abstract syntactic or semantic schemas that emerge from their use.

Given the labour intensive work required by this type of analysis, the focus is placed on the use of verbout constructions made by L2 learners of the PVs as reflected in a corpus of learner language, i.e. the Spanish, Italian, Swedish, Dutch, Russian and Bulgarian subsections of the ICLE (1,287,517 words). More concretely, I analyse L2 use of out-PVs at different grain levels and provide an account of the factors influencing the acquisition of these linguistic units. The results obtained from the analysis show 1) that out is underused by learners, at the lowest level of constituency, the level of the word and its collocates and that this may be due its low cue answer contingency (it is a short form with many meanings); 2) that out-PVs, as other formulaic sequences, shows a pattern of overuse of a small number of frequent verbs and underuse of the rest; 3) that, at a morpho-syntactic level, out-PVs used by L2 learners are typically frozen with little variability in both the tenses and the syntactic patterns chosen; and 4) that at the semantic level, more prototypical and frequent meanings in the text type analysed, not necessarily literal uses, are used with greater frequency by NNS. All in all, the usage-based approach adopted has allowed us to reveal the complexity of factors involved in explaining the difficulty L2 learners have in acquiring phrasal verbs.
\end{abstract}

Keywords: phrasal verbs, constructions, formulaicity, second language acquisition, corpus linguistics, particle OUT

\section{INTRODUCTION}

In the last few years, the role of formulaicity or formulaic language has been acknowledged (e.g. Wray 2002, Schmitt and Carter 2004) as one of the key elements explaining the difference in language use and learning between native (NS) and nonnative speakers (NNS) of English. More recent research has nuanced this broad finding by showing that underuse of formulaic sequences (FSs) by NNS is only part of the picture, which is completed by the tendency to overuse a small group of these linguistic units (Durrant and Schmitt 2009). The question remains, however, whether this gap in 
the knowledge between NS and NNS can simply be described in quantitative terms, i.e. NS use more FSs than NNS, or whether, if we restrict ourselves to linguistic factors, there are additional qualitative factors specifically tied to the nature and constituent parts of the formulae. In other words, the question that needs to be asked is whether NNS not only use fewer FSs than NS but also use them in a different way and whether, as suggested by Schmitt and Carter (2004), the constituent elements or individual words integrating the FS play a particular role in this process.

The above research programme starts from two main assumptions. The first one concerns the understanding of FSs as units that are not completely frozen or fixed. FSs can certainly show variability, flexibility and complexity at the different linguistic levels and this has been recognized by the different theoretical approaches (see Gries 2008, Moon 1998, for an overview). The second one, and here the theoretical differences are greater, is related to the fact that non-compositionality need not be absolute. Individual words contribute both syntactic (Konopka and Bock 2009) and semantic (Wulff 2009) information to the FSs.

Given this approach, phrasal verbs (PVs) become a perfect test bed to study the range of linguistic factors affecting the L2 acquisition of FS. They do not only show different syntactic or semantic configurations (e.g. transitive vs. intransitive, continuous vs. split, opaque vs. transparent, etc.), which make them subject to great variability. More importantly, following a usage-based approach, PVs can be described at different levels of abstraction ranging from lower level concrete constructions, which can be equated to specific uses taught to learners in EFL books (e.g. Put it out), to their highest schematic configuration defined in reference grammars (e.g. as verb+particle constructions). PVs are thus the perfect example to study the problems that variable and schematic FS are likely to pose to L2 learners.

However, the existing SLA research has focused on the problems that PVs as a group pose to NNS (Ishii and Sohmiya 2006, Siyanova and Schmitt 2007), thereby emphasizing their homogeneity and paying little attention to the different sources of variation. NNS are shown to avoid and/or underuse PVs and this is taken as a manifestation of their mostly idiomatic and formulaic status irrespective of specific linguistic factors involved. This is basically the result of the mostly experimental 
methodology used, which only allows the analysis of a limited number of PVs taken as representative of the whole phenomenon (however, see Waibel 2007). Moreover, PVs are defined exclusively following a structuralist approach (usually based on Quirk et al. 1985) which gives priority to syntax and semantic opacity and therefore disregards the chunking mechanism at play in cases of multiple constituency (she'd come out of the water cf. Cappelle 2005) and in non-compositional ones (e.g. go out). As research has shown, some of these sequences can become formulaic by dint of their frequent use.

It is the aim of this article to explore the acquisition of PVs by L2 learners from the perspective provided by a usage-based approach to language, which will take into consideration all levels of schematicity (from low scope or item-specific levels to the more abstract syntactic schemas). Thus, given the labour-intensive work required by this type of analysis, I will concentrate on the use of verb-out constructions made by L2 learners of the PVs as reflected in a corpus of learner language. This will allow me to start at the lowest level of analysis, the level of the word (in this case the word out), and proceed to study the construction at higher levels of abstraction that take into account meaning and syntax. In this way, I will look into L2 use of out-PV at different grain levels and will hopefully be able to provide a more thorough and detailed account of the factors that may influence the acquisition of these linguistic units.

The article is organized as follows. After an introduction on the different aspects involved in the acquisition of PVs and a summary of the main findings on L2 acquisition of PVs, I present the methodology and the main hypotheses. Then I will analyse the use of the particle out by L2 learners at different grain levels, first in isolation and then in combination with other words (i.e. its collocates), and finally I will concentrate on the main focus of the present article - its verbal patterns.

\section{WHAT IS INVOLVED IN L1 KNOWLEDGE OF PVS?}

\section{II.1. Lexis and/or grammar}

Following some of the research on the subject (Jackendoff 1997, 2002, 2010, but see also Cobb 2003), the task of acquiring PVs could be described as very similar to vocabulary acquisition. Given their phraseological status, these multi-word units would be stored, as also happens with other idioms, in the mental lexicon on an item-by-item 
basis. The knowledge native speakers have of PVs would then become part of their long-term memory together with their meanings and structural specifications (see Konopka and Bock 2009 for an account). Gauging the number of PVs known by a native speaker or, as in our case, by an L2 learner would amount to establishing their use of these multi-word units.

However, as Jackendoff (2002) himself acknowledges, this view does not provide us with a complete picture since there are at least two groups of what he calls verb particle constructions (VPCs) that do not need to be stored in the mental lexicon. The first one is instantiated by a sentence like I'm (all) coffeed out, where a verb and a noun can be substituted in the place of the verb with the meaning 'worn out from too much V-ing/too much N'. The second makes reference to verb-particle combinations such as flip out, phase out, chill out, etc. (2002: 188), which allow for much less variation in the verb slot and can roughly be paraphrased as 'go into an unusual mental state'. According to Jackendoff, in both cases the VPCs can actually be constructed online as they are respectively based on productive and semi-productive schemas that can give rise to new and non-conventionalised instances. In other words, there is a rule involved in their production.

Even though other researchers have shown that frequently productive constructions or schemas can also be stored in the mental lexicon (cf. Durrant and Schmitt 2009), Jackendoff's analysis emphasizes that a lexical approach to the acquisition of VPCs is not enough and that there is a higher level of abstraction involved in the knowledge of VPCs, i.e. the syntactic level. In fact, it is only at this level that VPCs can be identified since it is by looking at their specific syntactic structure that it becomes possible to distinguish them from similar expressions containing a preposition (e.g. he went down the street). As put forward by the linguistics literature (Cappelle 2005, Jackendoff 1997, 2002, 2010, Quirk et al 1985), the knowledge of PVs would involve being able to distinguish particles from prepositions, as these show different syntactic behaviour. This knowledge would obviously be implicit since very few native speakers, except perhaps for linguists, would be able to explain the difference between these two units. Very few studies, however, have explored whether this syntactic distinction between particles and prepositions entails a difference in the way they are learned and the difficulty they pose for native and non-native speakers. The present study intends to address this gap by 
studying the acquisition of out both when it functions as a preposition (e.g. He went out of the building) and when it does so as a particle (e.g. He went out).

\section{II.2. Semantic approaches to PV knowledge}

For some researchers (O’Dowd 1998, or Cappelle 2005 for a summary) grammatical knowledge is not entirely reliable and the syntactic status of particles has been problematized. Thus, even reference grammars (Huddlestone and Pullum 2002, for example) have opted for doing away with them and subsuming them under the blanket category of prepositions.

This decision is taken on the grounds that the semantic similarity between these two linguistic units should have priority. In Cognitive Linguistics, which is the approach that has paid greater attention to them, this semantic overlap has been explained in terms of semantic or metaphorical extension from their basic meaning. Thus, the spatiotemporal meaning of a preposition like over would be extended into a network of senses that have arisen by its use in other less specific and abstract contexts (Lakoff 1987), for example when it expresses control (Evans and Green 2006). This basic approach has been applied to other prepositions and has produced an extraordinary wealth of research (Brugman 1981, Campoy 1996, Coventry and Garrod 2004, Deane 1993, 2005, Dirven 2001, Evans 2003, Hampe, 2002, Lakoff 1987, Lindstromberg 1998, Morgan 1997, Navarro 2002, Silvestre 2009, Svorou 1994, Vandeloise 1991, 1994).

This new outlook on prepositions is made possible by the research on compositionality (e.g. Gibbs et al. 1989; Glucksberg 1993), which has shown that very few formulae or idioms are strictly non-compositional. In the case of PVs, this has even led to the elaboration of a measure of the contribution to the meaning of PVs by each of the component words (Berry-Rogghe 1974, cited in Wulff 2009).

This approach, however, is not without its critics, even within the field of cognitive linguistics. Thus, as Zlatev summarizes (2007: 341), both radial networks and the primacy of space have been called into question by experimental research (cf. Cuyckens et al. 1997, Rice et al. 1999, Sandra and Rice 1995) and have been said to lack psycholinguistic reality at the level of the individual speaker. But the evidence is still 
scarce and does not refute the existence of meaning connections or networks as such at a linguistic or conventionalized level (Zlatev 2007). The mind of the individual speaker may not exactly reflect the diachrony of the language and the way meaning networks were created, but it is unlikely that all the connections between related meanings remain obscure for him or her. On the other hand, the spatiotemporal senses may not necessarily be the basic meaning, but, as prototype theory predicts, other senses will take its place in the mental lexicon.

\section{II.3. PV Constructions}

This critique of the standard cognitive linguistic position on prepositions brings to our notice the fact that both the syntactic and, to a lesser degree, the semantic descriptions above assume an understanding of PVs by an ideal native speaker and a homogenous knowledge of all PVs. But this is not always the case, as shown by the example of children. Here, as pointed out by Tomasello, it seems more accurate to posit a more unsystematic and patchy knowledge: "a given child might use a lexical item like up in all kinds of interesting ways in all kinds of combinatorial patterns, but then use the very similar lexical items down and on only as single word utterances" (Tomasello 2000: 212). It can be argued that, although different in kind, L2 learners' knowledge of PVs can also be assumed to be patchy and unsystematic and that an analysis at a lower level of abstraction like the one carried out here with out is necessary.

In fact, as suggested by Jackendoff (2002), it would be more accurate, from a strict constructionist perspective, to posit six different constructions or, to use his own words, phenomena (Jackendoff 2010), since he can see no unity in their semantics: “There seems absolutely no semantic unity among these various phenomena, despite sharing the same syntax” (Jackendoff 2010: 249).

However, for a constructionist and usage-based approach to language, reconciling these three main perspectives need not be difficult, as they can be seen not as mutually exclusive but as complementary. Item-based, abstract syntactic knowledge, semantic and constructional knowledge form part of the inventory of 'symbolic units' that constitute language (Langacker 1987). Furthermore, it would be possible to establish the 
connection between the six phenomena Jackendoff makes reference to by positing the meaning of the particle as the axis uniting and giving coherence to them.

In short, an analysis wanting to explore the acquisition of PVs will have to take this into account. Here a multiple perspective is adopted by first focusing on the acquisition of the adverbial particle out and then by analysing its different syntactic and semantic features when it collocates with a verb.

\section{L2 ACQUISITION OF PVS}

The research on the acquisition of PVs can be divided into two main strands. On the one hand, we have the analyses carried out within the tradition of SLA acquisition proper and, on the other, there is a certain amount of CL-inspired research mainly focusing on language instruction.

As already stated in the introduction, SLA research has mainly focused on the avoidance of PVs, defined as the preference by L2 learners for one-word verbs over multi-word verbs when these would be the typical choice by native speakers. In strict terms, avoidance does not mean lack of knowledge but strategic behaviour on the part of the learner, who perceives these units as difficult and opts for those he or she considers to be easier.

Factors that have been found to affect avoidance of PVs are: 1) the L1 of the learner, with learners whose L1 is closer to English showing less avoidance (Dagut and Laufer 1985, Hulstijn and Marchena 1989, Sjöholm 1995); 2) the proficiency level of the learner (Liao and Fukuya 2004, but see Siyanova and Schmitt 2007 for a different opinion); 3) the idiomaticity of the PV (Dagut and Laufer 1985, Liao and Fukuya 2004, however, see Ishii and Sohmiya 2006 for different findings); and 4) the degree of control used in the task administered (Liao and Fukuya 2004).

Other SLA researchers have focused on an aspect that is related to avoidance but does not presuppose previous knowledge or a strategic behaviour on the part of the learner, i.e. underuse (Alejo 2010a, 2010b, Cobb 2003). This concept can be defined as the tendency to use on average fewer PVs than native speakers and is related to the lack of formulaic competence by L2 learners. 
Perhaps as a result of the methodology adopted, these SLA studies on PV acquisition do not touch on aspects that recent SLA research has highlighted. Thus, very little mention is made of frequency effects (see Alejo 2010, Alejo et al. 2010), Zipfian tendencies (Alejo et al. 2010) and other aspects such as saliency and construal. More importantly, the underlying assumption that these studies adopt is one whereby PVs are still perceived as a unitary phenomenon and not as a family of constructions (see Gries 2003, Dirven 2001) and pay little heed to the different sources of linguistic variation available for PVs in spite of their status as FS.

\section{RESEARCH QUESTIONS}

In this paper, I intend to analyse how this variability in PVs, and more particularly in PVs using the particle out, affects the way in which NNS of English acquire and use these formulaic sequences. In this respect, the following hypotheses can be put forward:

1. Starting at the lower level, the level of the word and its collocates, out is hypothesized to be underused by learners, as it is a short form with low cue answer contingency, i.e. several meanings and functions correspond to one form.

2. In line with what has been found for other types of collocations (see section VI.4.1.c. below), all L2 learners of English will use PVs to a lesser extent than NS, while at the same time showing a tendency to overuse highly frequent PVs.

3. Given that PVs show different syntactic and semantic configurations, which by using Construction Grammar could be identified as different constructions (Gries 2003), which separate them from phraseology or contiguous collocations, overuse and underuse of PVs by L2 learners will be modulated by these specific configurations.

\section{METHODOLOGY}

\section{V.1. Corpora used}

In this study, three different corpora were used. On the one hand, the ICLE (International Corpus of Learner English 2002) was used to establish L2 learners' use of out-PVs, while both the LOCNESS (Louvain Corpus of Native English Essays) and the 
university and school essay sections of the BNC served as the necessary benchmark against which learners' patterns of use would be compared.

The ICLE (2002) is a non-tagged corpus made up of short essays - 500 words - written by university students in Europe on different contentious topics. It is perhaps one of the best corpora available to study learner language and has a major advantage for the purposes of our study: it comprises texts from students of different L1 backgrounds. As stated in the introduction, language transfer plays a particularly important role in L2 use of PVs and therefore had to be factored out.

However, not all subcorpora included in the ICLE were selected, as this would have involved extensive work. At the same time a random selection was also methodologically problematic, given the demonstrated influence on PV acquisition of different L1 groups (cf. Dagut and Laufer 1985, Hulstijn and Marchena 1989), which has been confirmed and expanded by using cognitive criteria (Alejo 2010). As a result, in order to ensure a balanced sample of learner language, two subcorpora for each of the groups established by Alejo (2010b) were chosen (see Table 1).

Both the LOCNESS and the sections of the BNC used here fulfilled the requirement of comparability in terms of genre or text types. They mainly consist of argumentative essays like the ICLE and their total length is also equivalent to each of the individual subcorpora of the ICLE. The total numbers of words in the NS and NNS subsections are different but, as some of the calculations had to be performed on an individual basis (e.g. T-scores) and the overall figure was not very different, they were still deemed useful for comparative purposes.

Table 1. Corpora used.

\begin{tabular}{lll}
\hline & CORPUS & \# WORDS \\
\multirow{2}{*}{ NS } & BNC & 202,183 \\
& LOCNESS & 288,177 \\
\hline \multirow{4}{*}{ NNS } & DUTCHICLE & 231,322 \\
& SWICLE & 198,705 \\
& RUSSICLE & 227,648 \\
& BULGICLE & 199,951 \\
& SPICLE & 200,931 \\
& ITICLE & 228,960 \\
\hline
\end{tabular}




\section{V.2. Procedure}

Given its commitment to a usage-based approach, the present study aims to conduct a comprehensive analysis and comprises all the hits of the word out found in the corpora, irrespective of function or meaning. Its main focus, however, is restricted to out-PVs (i.e. PVs containing the word out). It is important to note that the scope of the present analysis and the terminology used is best defined by reference to Dirven's (2001) classification. Following mostly a cognitive linguistic approach, and therefore using semantic criteria (see section above), he also recognizes the special syntactic status of some of these constructions. Thus, he differentiates between PVs as a broad term including combinations of verbs and prepositions or particles and VPCs as a subcategory within that includes only particle combinations, the ones complying with syntactic tests (Dirven 2001: 5).

No other similar lexical items (e.g. up, down, off, etc.) were included in the analysis because a detailed usage-based analysis like the one proposed here would not be possible if the scope of analysis were wider. At the same time, selecting out fulfils some important conditions. In the first place, together with up, out is one of the most frequent particles (Gardner and Davies 2007, O’Dowd 1998) and is likely to provide us with a good example of what may happen with PVs made up of other constituents. Moreover, for the analyst, out provides the advantage of having neatly distinct particle and prepositional uses (nearly always followed by the preposition of) and therefore making it easier to distinguish between these two uses and categorize them. As some of the research on lexical acquisition has demonstrated, automatic extraction of VPCs is far from achieving a high degree of accuracy (cf. Villavicencio, Bannard, etc.) and in addition there are times where the analysis may be unclear (cf. O’Dowd 1998).

All instances of the word out, irrespective of meaning or function, were obtained by using the application WordSmith Tools. A first methodological step consisted in identifying its collocations and in measuring the collocational strength of the resulting pairs. For this, the programme Collocate was used and the test chosen to calculate the collocational strength was the T-score. Even though some flaws have been pointed out (Stefanovitch and Gries 2003), this test is still widely used and has the advantage of taking into account highly frequent collocations (cf. Durrant and Schmitt 2009). Given 
the importance of frequency in constructional approaches (cf. Ellis 2002, Ellis and Ferreira-Junior 2009, Wulff 2008) and in the present paper, this test allowed us to select those instances we were more interested in.

However, as we are dealing with constructions, collocational strength was only useful to measure adjacent pairs since, as Durrant and Schmitt state, “combinations at a wider range of distances ran the risk of making association measures non-comparable between collocations” (2009: 166). In this case, raw and normalized frequencies were considered appropriate following standard procedures in corpus linguistics.

Once identified, all the instances of out were lemmatised and exported to Excel format by using a functionality to that effect. A database was created from the resulting Excel file and the following tags were added manually:

1. Meaning of the particle. A slight reformulation and simplification of the radial network provided by Tyler and Evans (2003). According to this classification, the central meaning or proto-scene of out, exteriority, is typically expressed in meanings of motion and location. This basic meaning is extended into various other meanings, which can be interpreted to have developed as meaning extensions. Among other meaning extensions, not included here given their low frequency, they mention the following major senses: a) perception and cognition (Tyler and Evans 2003) (e.g. find out the truth); b) exclusion and invisibility (e.g. he crossed out the typo); c) segmentation, which comprises distribution and reflexivity (e.g. the boy stretched out his hand); d) completion (e.g. this jacket needs to dry out); e) material source, which is the only meaning that is specific to the preposition out of included in this analysis, and refers to those instances where the preposition indicates what something is made of (e.g. the chair was made out of wood).

2. Grammatical constituency of out including three main categories: a) nominal, i.e. when out was part of a compound which was either a noun or an adjective (e.g. crowding out); b) adjunctive, when the preposition or adverb function is outside the scope of the verb usually functioning as an adjunct; and c) verbal (PVs), when out functions within the scope of the verb as a particle or as a 
preposition. As suggested above (cf. Dirven 2001), this category includes VPCs but does not identify with them, as it subsumes them.

3. Grammatical status of verbal out differentiating between out-VPCs, where out has the syntactic and semantic properties of a particle, and 'verb+out' constructions, which comprise the rest of the uses.

4. Syntax of VPCs, which was tagged for the following structures: a) intransitive VPCs; b) contiguous, when the particle is placed after the verb and before the direct object (He sorted out the situation); c) split, when the direct object is placed before the particle (I sorted it out); and d) stranded (Something I did not find out).

\section{RESULTS AND DISCUSSION}

\section{VI.1. Frequency: how much do L2 learners use the word out?}

Since the aim of this article is to study the acquisition of PVs comprising the particle out, it seems reasonable (and also appropriate from a usage-based perspective) to start at the lowest level by analysing the extent to which the word out is used by L2 learners. Its frequency of use may provide us with a first approximation to the knowledge they have of this form.

In ICLE, as already established by Granger and Rayson (1998), out ranks in the $96^{\text {th }}$ position of the 100 most frequent words, which seems a clear indication that learners use it quite productively and that it constitutes one of the items of their basic vocabulary. This replicates, with a slight difference in rank, what happens with NS, where the word out is also included in the list of the 100 most frequent words.

However, the similarities with native speaker use of the word out disappear if we look at the actual normalized frequency with which both groups use it. As can be seen from Table 2, NNS use the word out per million words nearly half as much as NS. In fact, every 100 times out is used by NNS it will be used, on average, 140 times by a NS. 
Table 2. Frequency of out.

\begin{tabular}{l|l|l|}
\hline & $\#$ & p.mil. \\
\hline NS & 876 & 1786 \\
\hline NNS & 1612 & 1252
\end{tabular}

In short, L2 learners know the word out but underuse it. This is clearly related to an already established tendency in learner corpora to underuse function words and more particularly prepositions (Granger and Rayson 1998) and is also an indication that there is something in the way NS use out that escapes L2 learners. The present article will attempt to provide an explanation for this finding.

\section{VI.2. Collocates: do learners know the company out keeps?}

After considering out in isolation, the second level of analysis deals with the different words it associates with, i.e. its collocations. A collocational analysis may provide further clues as to the way out is used in constructions by NS and the way learners reproduce those constructions or deviate from them.

The results for the T-scores presented in this section have been calculated for each subcorpus and then averaged out for both NS and NNS. Thus, it was possible to compare T-scores, a measure which is dependent on corpus size. As some combinations of out are not found in all subcorpora, especially NNS subcorpora, I have only included collocates appearing a minimum of 4 times (1 NS subcorpus and 3 NNS subcorpora).

\section{VI.2.1. Right collocates}

The right collocates for out in NNS corpora roughly correspond with those in NS, as can be seen from Table 3. Thus, with the exception of 'out what', 'out their' and 'out in', the rank order is similar in both groups. 
Table 3: right collocates for out.

\begin{tabular}{|l|l|l|l|l|l|l|}
\hline \multicolumn{9}{|l|}{} & NS & \multicolumn{7}{|l|}{} & \multicolumn{2}{l|}{ NNS } & \\
\hline N.GRAM & $\#$ & \# corpora & T-Score & \# & \# Corpora & T-Score \\
\hline out of & 196 & 2 & 8.5084455 & 459 & 6 & 7.658805667 \\
\hline out that & 37 & 2 & 2.875499 & 141 & 6 & 3.631427833 \\
\hline out to & 59 & 2 & 2.8077225 & 116 & 6 & 2.147978667 \\
\hline out on & 18 & 2 & 2.2360315 & 16 & 3 & 1.592677333 \\
\hline out by & 15 & 2 & 1.917134 & 17 & 4 & 1.56093275 \\
\hline out what & 5 & 1 & 1.886924 & 19 & 4 & 1.7147175 \\
\hline out but & 5 & 1 & 1.457633 & 15 & 3 & 1.400459 \\
\hline out their & 10 & 2 & 1.44653 & 10 & 3 & 0.936769667 \\
\hline out in & 28 & 2 & 1.3997625 & 47 & 6 & 0.562578667 \\
\hline out from & 4 & 1 & 1.246068 & 17 & 4 & 1.666419 \\
\hline out there & 4 & 1 & 1.212829 & 14 & 3 & 1.49676933 \\
\hline out for & 14 & 2 & 1.128472 & 26 & 4 & 1.4979615 \\
\hline out the & 68 & 2 & 1.0884425 & 106 & 6 & 0.5810205 \\
\hline out a & 24 & 2 & 0.8578945 & 29 & 5 & -0.294445 \\
\hline out as & 11 & 2 & 0.6059145 & 15 & 3 & 1.252079667 \\
\hline out and & 22 & 2 & -0.4253065 & 48 & 6 & -0.04628233 \\
\hline
\end{tabular}

It is interesting to note that the high T-scores indicate that L2 learners are aware of 1) the strong association of out and of, forming what structural grammars (Quirk et al. 1985) call a complex preposition; and 2) the preference of out to be followed by clause initiators such as 'that', 'to' or 'what', which is also an indication of its preference to collocate with verbs on the left-hand side (see Figure 1).



Figure 1. Summary of right collocations. 
At the same time, learners show a weaker association of out with 'in', 'on' and 'by', which seems to indicate that the construction 'out + preposition' is difficult for them, with the exception of out of (see Figure 1).

Table 4. Frequency of out of.

\begin{tabular}{l|l|l|}
\hline & $\#$ & p.mil. \\
\hline NS & 238 & 483 \\
\hline NNS & 472 & 367
\end{tabular}

From a CL perspective, the underuse of out by NNS may be the result of a greater cognitive effort required, since when out is used intransitively the landmark must be retrieved from the context, whereas in the case of out of the landmark is always present.

\section{VI.2.2. Left collocates}

The left collocates for out are also very similar for both NS and NNS (see Table 5). Most of them correspond, with the exception of 'way out', to reporting forms of verbs, which are typical of argumentative texts. It can also be noticed that they are tokens of a small group of PVs whose use seems to be entrenched in both groups (turn out, point out, find out and carry out).

Table 5. Left collocates for out

\begin{tabular}{l|llll|lll}
\hline & \multicolumn{3}{|l}{ NS } & & \multicolumn{3}{|c}{ NNS } \\
\hline & \multicolumn{3}{|c}{ cor- } & & \multicolumn{3}{c}{ Cor- } \\
N.GRAM & $\#$ & pora & T-Score & $\#$ & pora & T-Score \\
\hline points out & 43 & 2 & 4.5423 & 13 & 3 & 2.0548 \\
carried out & 34 & 2 & 4.1074 & 35 & 5 & 2.5338 \\
way out & 15 & 1 & 3.6875 & 60 & 6 & 2.8230 \\
carry out & 20 & 2 & 3.1276 & 30 & 5 & 2.4066 \\
find out & 20 & 2 & 3.0870 & 78 & 6 & 3.5141 \\
go out & 18 & 2 & 2.9113 & 60 & 5 & 3.3110 \\
get out & 18 & 2 & 2.7897 & 32 & 6 & 2.0882 \\
pointed out & 6 & 1 & 2.4438 & 35 & 5 & 2.6330 \\
point out & 6 & 1 & 2.3756 & 71 & 6 & 3.3527 \\
turns out & 11 & 2 & 2.2643 & 64 & 5 & 3.3507 \\
turn out & 8 & 2 & 1.9568 & 40 & 5 & 2.7333
\end{tabular}




\begin{tabular}{l|lll|lll} 
them out & 5 & 1 & 1.8580 & 17 & 4 & 1.6192 \\
turned out & 10 & 2 & 1.7987 & 30 & 4 & 2.6384 \\
found out & 7 & 2 & 1.7569 & 28 & 5 & 2.3009 \\
it out & 5 & 1 & 0.1441 & 12 & 3 & 0.0116 \\
calling out & & & & 19 & 3 & 2.4227 \\
work out & & & & 28 & 5 & 2.1211 \\
going out & & & & 12 & 3 & 1.9081 \\
is out & & & & 19 & 5 & -0.8588 \\
\hline
\end{tabular}

\section{VI.3. Learner awareness of out constituency}

At a higher level of abstraction, out enters three broad configurations: 1) nominal constructions such as noun compounds (way out, time out), nominalizations of PVs ${ }^{1}$ (her coming out) and adjectival phrases functioning as complements or attributes of nouns (out of control, out of the question); 2) adverbial constructions which mostly comprise those instances where out is part of phrases functioning as an adjunct outside the scope of the verb (we did it out of respect); and 3) verbal constructions, which constitute the focus of the present article.

As can be seen from Figure 2, it is when out enters a verbal syntactic configuration that L2 learners have greater difficulty in reproducing native speaker use. The other configurations, mostly consisting in a reduced number of entrenched constructions, do not pose any problem for learners. Some instances of the latter are, for example, the NUMBER out of NUMBER construction (e.g. three out of ten).

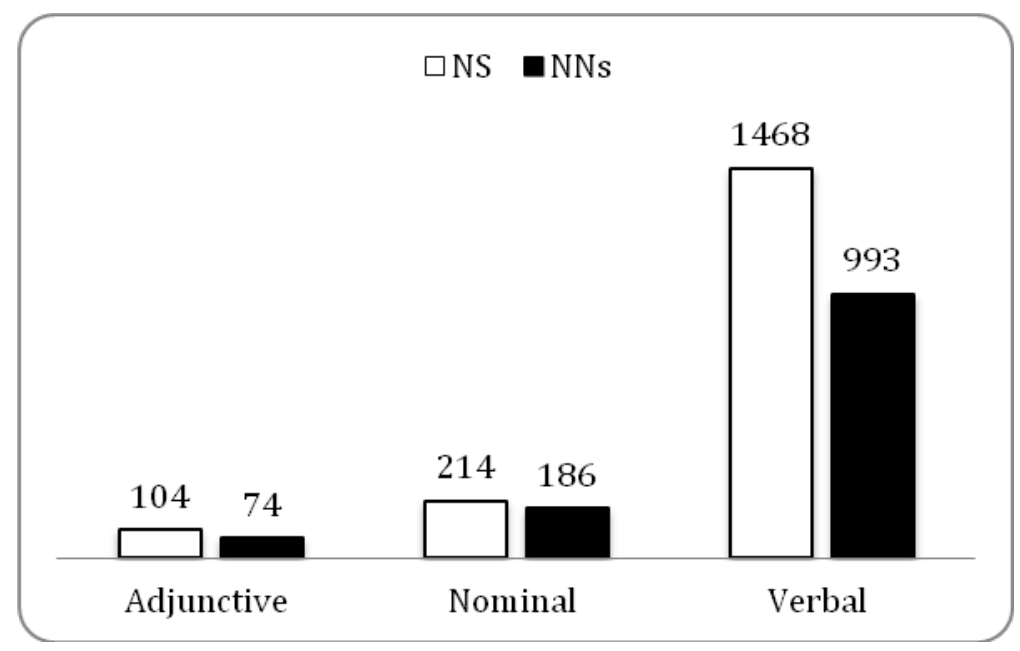

Figure 2: Syntactic configurations of out.

\footnotetext{
${ }^{1}$ I have not included nominalizations of PVs in my analysis following the arguments provided by Goldberg (2006: 23) that both the syntax and the semantics of derived nouns are different from their verbal counterparts.
} 
To sum up, the great difference in the frequency of use of the word out between NS and NNS is not the result of a divergent use of specific collocations by NNS, but the consequence of underuse of the verbal schematic configuration this word usually enters. Whether this verbal schematic configuration can be equated with PVs is a question that is mostly decided on theoretical grounds, as we have seen in the introduction. In the next section, I will analyse the quantitative impact of such a decision.

\section{VI.4. Verbal out}

Once I have explored the different immediate linguistic contexts of the word out, I will focus here on what constitutes the centre of the present article, i.e. on verbal out or, using CL terminology, on out-PVs.

This analysis will involve situating ourselves at different levels of abstraction.

At the highest level of abstraction, I will consider the construction represented by a verb and the preposition out [of], a schema that is mostly syntactic in nature and that - as we saw in the introduction - only captures the grammar.

However, given the understanding of PVs as a network of constructions I have adopted, the analysis can only proceed by taking into account other elements, such as frequency and meaning.

\section{VI.4.1. Frequency and entrenchment}

From a CL point of view, frequency is assumed to be an important factor insofar as it has a strong connection with usage-based approaches.

\section{VI.4.1.a. Token/Type frequency}

The frequency of out-PVs was already shown in Figure 2 above, where we can see a comparison of the verbal out construction used by both NS and NNS. Although out-PVs are highly frequent in both groups, especially if we compare them to the other configurations in which out appears, they are more frequent in the group of NS. NNS seem to experience greater difficulty with the acquisition of out-PVs, a corroboration of their problems with PVs in general. 
However, as usage-based approaches have shown (Bybee 2007), the best indicator that a schematic construction has been acquired is its type frequency, as this figure is the one that expresses the productivity of a schematic construction. According to this, we can see (Figure 3) that NNS' mastery of out-PV constructions is further from NS use than token analysis initially pointed out.

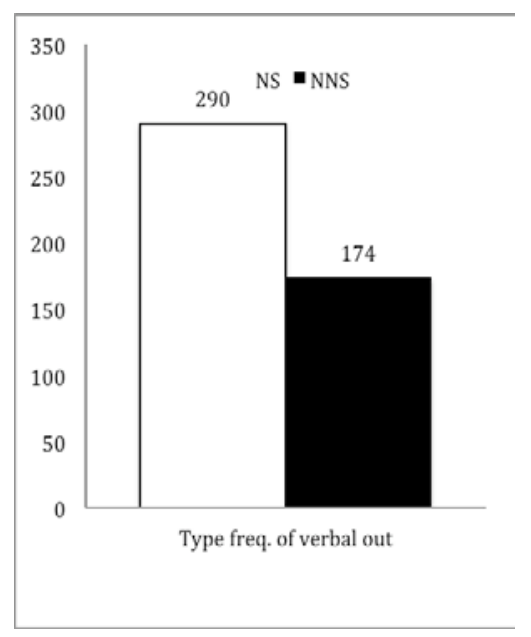

Figure 3. Type frequency.

\section{VI.4.1.b. Frequency effects}

The above results do not mean that NNS are totally unaware of the frequency with which NS use specific out-PVs. In fact, as can be seen from Figure 4, NNS' use of outPVs shows frequency effects since, with the exception of some outliers such as carry out and turn out, the frequency band of the first 25 out-PVs is not very different from that of NS. Moreover, their frequency of use also represents a typical Zipfian curve, where a small number of items usually share the bulk of use.

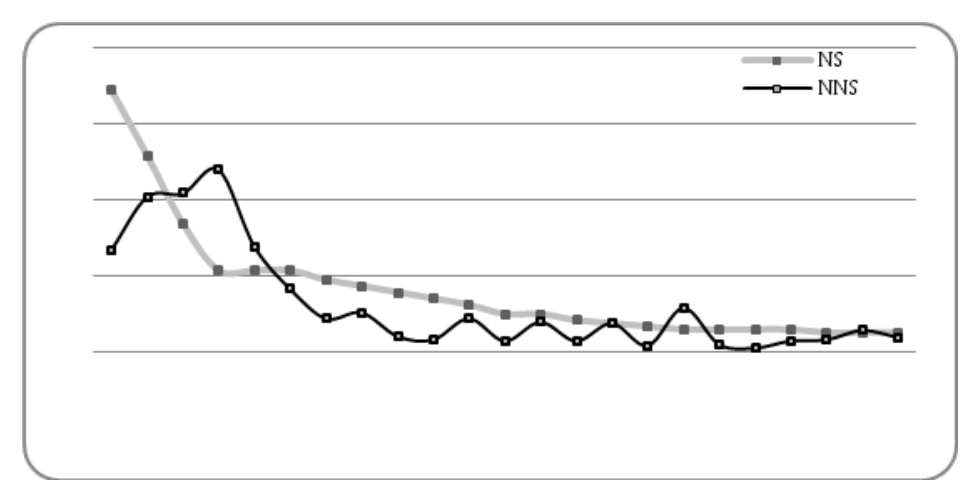

Figure 4. Most frequent out-PVs. 


\section{VI.4.1.c. Overuse as the flip side of underuse}

A final consideration regarding the frequency of out-PVs concerns a special phenomenon identified in L2 use of formulaic language. L2 learners have been shown to overuse a small set of formulaic sequences in comparison with NS (Cobb 2003, Durrant and Schmitt 2009).

As can be seen from Table 6, this is also the case of the particular formulaic sequences analysed in this article, i.e. out-PVs. Thus, the most frequent verbs (40) used by NNS account for nearly $90 \%$ of all out-PV tokens, whereas the same number of types only accounts for just over $75 \%$ in NS essays. In other words, in acquiring out-PVs, learners seem to have the same difficulties they have when acquiring other formulaic expressions. They can be successful in acquiring a small set of formulae but seem to strive to achieve a native or native-like mastery of these formulae. This finding is complementary to the low type frequency detected in section VI.4.1.a.

Table 6. NNS' overuse of the most frequent out-PVs.

\begin{tabular}{|l|l|l|l|l|}
\hline & NS & & \multicolumn{2}{|c|}{ NNS } \\
\hline & \# & \% & $\#$ & $\%$ \\
\hline $\begin{array}{l}\text { Top } \\
\text { PVs }\end{array}$ & 379 & 76.25 & 769 & 88.18 \\
\hline Rest of & & & & \\
\hline PVs & 118 & 23.75 & 103 & 11.82 \\
\hline Total & 497 & 100 & 872 & 100 \\
\hline
\end{tabular}

This phenomenon of overuse is not restricted to a number of types of out-PVs. It bears upon the different morphological variants or forms of the verbs. Thus, while there are certain forms that are dispreferred by NNS, such as the gerund or the past participle, the infinitive is clearly overused.

A similar overuse of the infinitive, and concomitant underuse of the other verb forms, was already a trend in learner language for all lexical verbs (Granger and Rayson 1998: 129). However, the pattern found for out-PVs may be considered as more marked (see Figure 5). 


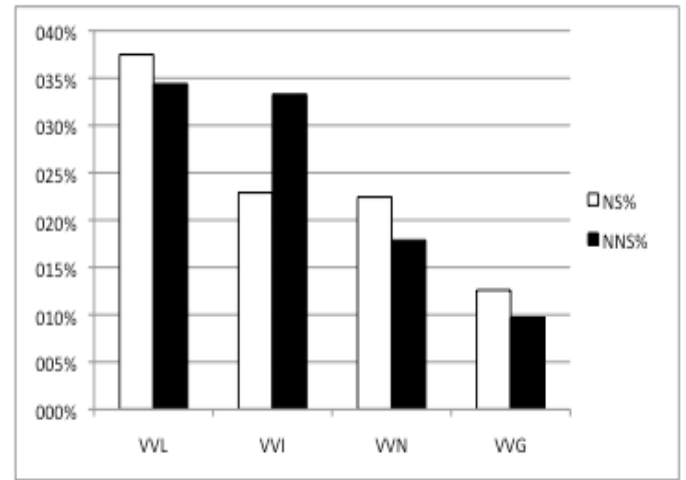

Figure 5. Percentage of verbal tags.

\section{VI.4.2. Syntax}

The role of syntax in the acquisition of PVs can be noticed, in the first place, by looking at the two broad subgroups that can be defined by drawing a distinction between verbs followed by particles, i.e. Verb Particle Constructions or VPCs (see Dirven 2001), on the one hand, and those followed by adverbs and prepositions, on the other. Thus, the former group would have a greater degree of fixedness since, even though transitive verbs allow the discontinuous configuration, particle movement is limited and no adverbial phrases are allowed between the verb and the particle. On the other hand, the latter group would allow a greater degree of syntactic freedom since, for example, both adverbs and prepositions can be fronted (e.g. out they went).

As can be seen from Figures 6 and 7, the combination of verbs and particles is by far the most frequent construction in both NS and NNS writing and is also the most productive, as is shown by the greater number of types. This was to be expected given that out, unlike similar function words such as in or off, is not frequently used as a preposition or as an adverb, as shown by O’Dowd (1998).

However, even though NNS realize the frequency of VPCs, they underuse them by comparison with NS. The extent of underuse is already noticeable if the number of tokens is considered (see Figure 6), but becomes really remarkable when we look the number of types (see Figure 7). If out-PV was already a very low productivity schema for NNS, VPCs are even less productive. 


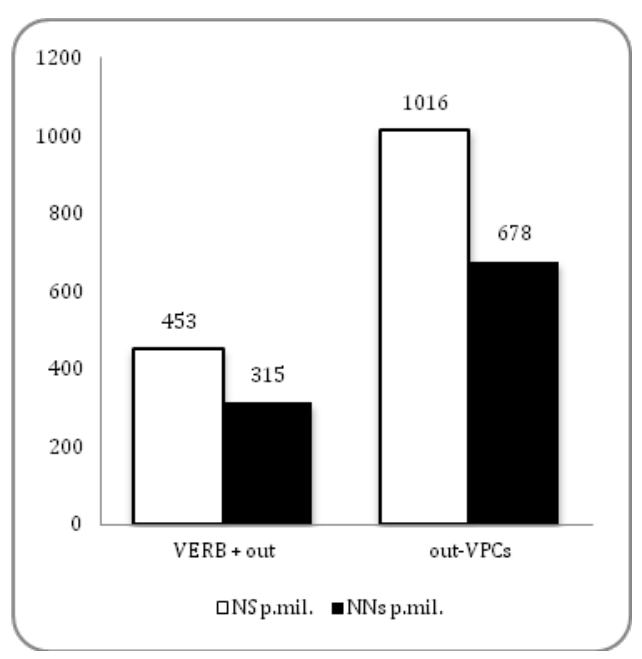

Figure 6: out tokens.

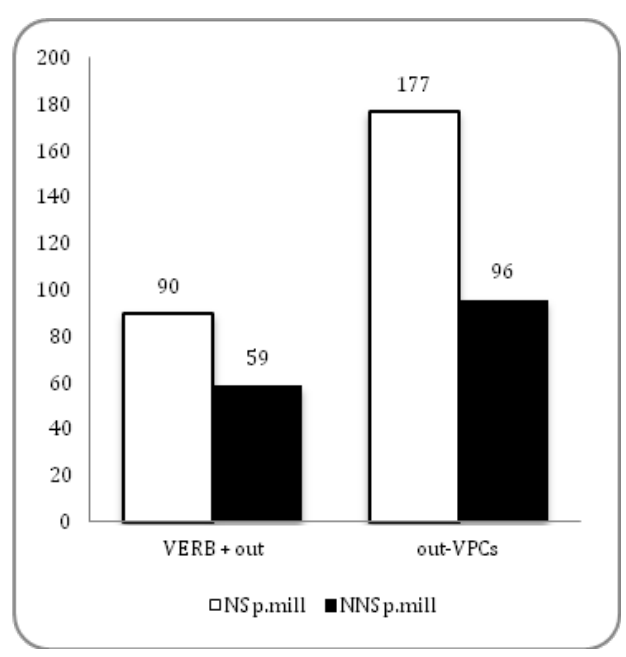

Figure 7: out types.

Table 7: Syntactic configurations of PVs

\begin{tabular}{|l|l|l|l|l|l|}
\hline out-VPCs & NS & & NNS & & Ratio \\
\hline & $\#$ & p.mil. & $\#$ & p.mil & \\
\hline CONTINUOUS & 229 & 467 & 558 & 433 & 1.1 \\
\hline INTRANSITIVE & 130 & 265 & 151 & 117 & 2.3 \\
\hline SPLIT & 36 & 73 & 28 & 22 & 3.4 \\
\hline STRANDED & 102 & 208 & 135 & 105 & 2.0 \\
\hline
\end{tabular}

When the specific syntax of the VPC subgroup is analysed (see Table 7), we can observe that NNS show a strong preference for the transitive continuous construction (e.g. 'He finds out that Jim is hidden' DUTCHICLE), particularly when followed by a clause, as already indicated in section VI.2.1 above. However, the rest of the syntactic configurations are much less frequently used by NNS, especially when the direct object is inserted between the verb and the particle in the split construction (e.g. 'They can vote representatives out' BNC), where the proportion of underuse goes from 1 to nearly 3 and a half.

Some of these results are somewhat surprising. Thus, one would presume that both the transitive continuous and the intransitive configurations would pose the same degree of 
difficulty for NNS. In both cases, the verb and the particle are not separated and the main task of the L2 learner is to parse them as a unit. The underuse of split and stranded configurations were much more expected for precisely the opposite reason.

The CL perspective adopted here can shed some light on both results. Thus, what we have called split corresponds to construction 2. As Gries (2003) points out, this construction is preferred when the direct object is easily retrievable from the discourse context or/and has a high degree of entrenchment. This is why it is more appropriate for objects requiring a limited amount of consciousness. It seems only natural that NNS have more difficulty in retrieving the context and possess fewer well-entrenched objects when writing and their written production would rely more on conscious elaboration (hence the overuse of the continuous configuration), rather than on automatic processing, which would explain why they underuse the split construction.

The greater underuse of the intransitive VPCs poses a greater challenge for a CL explanation. It could be that, as Dirven (2001) explains, intransitive constructions are the farthest from the original construction, where the preposition retained the prototypical locational meaning.

\section{VI.4.3 Semantics of prepositions}

From a CL point of view, a key factor to explain the acquisition of PVs lies in the meaning of the prepositions, as they are considered to carry a great deal of the meaning of the whole multi-word verb. It is by analysing the radial network of meaning a preposition has that we can begin to understand the radial network of PV constructions to which they give rise.

Overall, NNS' use of the different meanings of out found in out-PVs reproduces the shape of NS radiality of meanings (see Figure 8), although with areas in which this NNS shape clearly shrinks with respect to that of NS. In other words, NNS seem to be aware of the frequency of the different meanings of out, but their actual use fails to reproduce NS use, except for those instances where out expresses perception/cognition (e.g. point out). Particularly noticeable is the scarce use of motion/location and completion out-PVs. 
All the different meanings, except again for perception/cognition, have a lower productivity in NNS writing than in NS, as shown by Table 8. It would appear that NNS have only become aware of the productivity of this meaning.

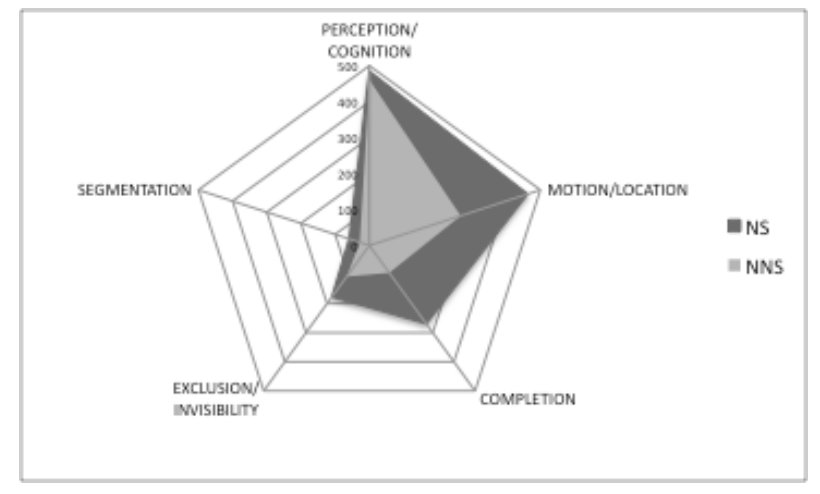

Figure 8. Radiality of meanings.

Table 8: Token frequency of meanings.

\begin{tabular}{llllll}
\hline Tokens & NS & \multicolumn{2}{c}{ NNS } & \multicolumn{2}{c}{ Ratio } \\
\hline & $\#$ & p.mil. & $\#$ & p.mil & \\
\hline PERCEPTION/COGNITION & 238 & 485 & 593 & 461 & 1.1 \\
MOTION/LOCATION & 227 & 463 & 344 & 267 & 1.7 \\
COMPLETION & 132 & 269 & 121 & 94 & 2.9 \\
EXCLUSION/INVISIBILITY & 87 & 177 & 138 & 107 & 1.7 \\
SEGMENTATION & 29 & 59 & 36 & 28 & 2.1 \\
M-SOURCE & 7 & 14 & 46 & 36 & 0.4 \\
\hline
\end{tabular}

Table 9: Type frequency of meanings.

\begin{tabular}{l|ll|ll|l}
\hline Types & NS & \multicolumn{2}{|l|}{ NNS } & Ratio \\
\hline & $\#$ & p.mil. & $\#$ & p.mil & \\
\hline MOTION/LOCATION & 72 & 103 & 68 & 60 & 1.7 \\
EXCLUSION/INVISIBILITY & 45 & 64 & 42 & 37 & 1.7 \\
PERCEPTION/COGNITION & 37 & 53 & 39 & 34 & 1.5 \\
COMPLETION & 31 & 44 & 24 & 21 & 2.1 \\
SEGMENTATION & 15 & 21 & 12 & 11 & 2 \\
M-SOURCE & 3 & 4 & 13 & 11 & 0.4 \\
\hline
\end{tabular}

\section{CONCLUSION}

Taking the word out as the starting point of my research, this paper compares the way in which it collocates in the language used by NS and NNS of English, with special attention to its verbal collocations. Following a usage-based approach, this comparison has attempted to include all the possible levels of analysis, ranging from its participation in low scope constructions (way out) to the more abstract syntactic and semantic levels. 
I thus aimed to reveal some of the linguistic factors that may play a role in L2 learners' acquisition of variable formulaic sequences such as PVs.

The main purpose of this paper has been to show how the linguistic behaviour of PVs can have an impact on their acquisition by NNS of English. On this point it can be said that I adopt a different perspective from the research on PV acquisition, which, as shown in the introduction, has mostly focused on extralinguistic factors such as the L1 of the learners or the amount of exposure, typically represented by the length of residence in an English-speaking country or the level of the students.

From the analysis at the lowest level of schematicity, the one that focuses on the collocates of out, we can see that L2 learners use out in similar ways to NS, especially when it appears in the complex preposition out of or in combination with words marking a clause boundary (i.e. followed by to-inf, wh- words, if, that, etc.). The first finding is not difficult to explain, as out of poses fewer cognitive demands on the learners, since the landmark is expressed and it is perceptually more salient than out. The second result is less obvious, but may be related to the strength of collocation of out with argumentative verbs, which are frequent in the text types used in our corpus (e.g. turn out, point out, find out, etc.).

However, even if learners are aware of the collocation of out with these argumentative verbs, the present research also shows that they mostly underuse out when it is employed in the context of a verbal phrase. This general trend of underuse is combined with an apparently contradictory tendency to overuse the most frequent verbs. This is confirmation of previous findings in the literature on formulaic language (Cobb 2003, Durrant and Schmitt 2009). NNS do not just avoid using out-PVs as was suggested by earlier literature (see section on PV acquisition above). Rather they rely on a small group, which is very frequent in their input. On the other hand, they have more difficulty with the ones in the low frequency band. Following Ellis and Ferreira-Junior (2009), it could be suggested that learners overuse the prototypical exemplars of argumentative discourse, while at the same time failing to be aware of the full range of verbs that are used by NS. In other words, learners show low type frequency and this indicates that they have not fully developed an abstract representation of the verbal+out 
construction yet. They seem to rely more on memorized chunks than on a productive use of this construction (cf. Goldberg 2009).

Further confirmation of this lack of abstract representation, i.e. of a construction that is more schematic, is provided by the frozen morphological and syntactic use of these verbs. NNS' preference to use out-PVs in the infinitive and their bias for the continuous syntactic order are a clear indication that they avoid variability and that they prefer to adopt a conservative stance as regards formulaic language (cf. Durrant and Schmitt 2009) not only by actively producing a small number of out-PV types, but also in the way they use them.

Finally, from a semantic point of view, learners seem to reproduce the frequency of meanings used by NS, but clearly underuse less prototypical meanings such as completion and segmentation.

\section{REFERENCES}

Alejo, R. 2010a. "L2 Spanish acquisition of English phrasal verbs: A cognitive linguistic analysis of L1 influence”. In Campoy, M.C., B. Bellés-Fortuno and M.Ll. Gea-Valor (Eds.) Corpus-Based Approaches to English Language Teaching. London/New York: Continuum, 149-166.

Alejo, R. 2010b. "Making sense of phrasal verbs: A cognitive linguistic account of L2 learning”. AILA Review 23: 50-71.

Alejo, R., Piquer, A. and Reveriego, G. In press. "Phrasal verbs in EFL course books”. In De Knop, S., F. Boers and A. De Rycker (Eds.) Fostering Language Teaching Efficiency through Cognitive Linguistics. Berlin/New York: Mouton de Gruyter.

Barlow, M. 2004. Collocate 1.0. Athelstan. http://www.athel.com/colloc.html

Brugman, C. 1981. Story of Over. M.A. thesis, Department of Linguistics, Berkeley: University of California.

Bybee, J. 2007. Frequency of Use and the Organization of Language. New York/Oxford: Oxford University Press. 
Campoy, M.C. 1996. Semantic Analysis of Adverbial, Prepositional and Adverbial Prepositional Verbs. Castellón: Unversitat Jaume I.

Cappelle, B. 2005. Particle Patterns in English. A Comprehensive Coverage. Ph. D. Dissertation, Faculteit Letteren, Leuven, Belgium: Katholieke Universiteit Leuven.

Cobb, T. 2003. “Analyzing late interlanguage with learner corpora: Quebec replication of three European studies”. Canadian Modern Language Review 59: 393-423.

Coventry, K.R. and Garrod, S.C. 2004. Saying, Seeing, and Acting: The Psychological Semantics of Spatial Prepositions. New York: Psychology Press, Taylor \& Francis.

Cuyckens, H., Sandra, D. and Rice, S. 1997. "Towards an empirical lexical semantics”. In Smieja, B. and M. Tasch (Eds.) Human Contact through Language and Linguistics. Frankfurt am Main: Peter Lang Verlag, 35-54.

Dagut, M. and Laufer, B. 1985. “Avoidance of phrasal verbs: A case for contrastive analysis”. Studies in Second Language Acquisition 7: 73-79.

Deane, P.D. 1993. "At, by, to, and past: An essay in multimodal image theory”. Proceedings of the Annual Meeting of the Berkeley Linguistics Society 19: 112124.

Deane, P.D. 2005. "Multimodal spatial representation: on the semantic unity of over”. In Hampe, B. and J.E. Grady (Eds.) From Perception to Meaning. Image Schemas in Cognitive Linguistics. Berlin/New York: Mouton de Gruyter, 235-282.

Dirven, R. 2001. “English phrasal verbs: Theory and didactic application”. In Pütz, M., S. Niemeier and R. Dirven (Eds.) Applied Cognitive Linguistics (2 Vols.). Berlin/New York: Mouton de Gruyter, 3-27.

Durrant, Ph. and Schmitt, N. 2009. “To what extent do native and non-native writers make use of collocations”. IRAL 47, 157-177.

Ellis, N.C. 2002. "Frequency effects in language acquisition: A review with implications for theories of implicit and explicit language acquisition”. Studies in Second Language Acquisition 24, 143-188. 
Ellis, N.C. and Ferreira-Junior, F. 2009. "Constructions and their acquisition: Islands and the distinctiveness of their occupancy". Annual Review of Cognitive Linguistics 7: 187-220.

Evans, V. and Green, M. 2006. Cognitive Linguistics. An Introduction. Edinburgh: Edinburgh University Press.

Gibbs, R.W. and Nayak, N.P. 1989. "Psycholinguistic studies on the syntactic behavior of idioms”. Cognitive Psychology 21:100-38.

Gardner, D. and Davies, M. 2007. "Pointing out frequent phrasal verbs: A corpusbased analysis”. TESOL Quarterly 41: 339-359.

Granger, S. and Rayson, P. 1998. “Automatic profiling of learner texts”. In Granger, S. (Ed.) Learner English on Computer. London/New York: Longman, 119-131.

Gries, S. 2003. Multifactorial Analysis in Corpus Linguistics: A Study of Particle Placement. London/New York: Continuum.

Gries, S. 2008. "Phraseology and linguistic theory: A brief survey". In Granger, S. and F. Meunier (Eds.). Phraseology: An Interdisciplinary Perspective. Amsterdam/ Philadelphia: John Benjamins, 3-25.

Hampe, B. 2002. Superlative Verbs: A Corpus Based Study of Semantic Redundancy in English Verb Particle Constructions. Tübingen: Narr.

Huddleston, R.G. and Pullum, G.K. 2002. The Cambridge Grammar of the English Language. Cambridge: Cambridge University Press.

Hulstijn, J.H. and Marchena, E. 1989. "Avoidance: Grammatical or semantic causes?” Studies in Second Language Acquisition 11: 241-255.

Ishii, Y. and Sohmiya, K. 2006. "On the semantic structure of English. Spatial particles involving metaphors”. In Yoshitomi, A. (Ed.) Readings in a Second Language Pedagogy and Second Language Acquisition: In Japanese Context. Amsterdam/Philadelphia: John Benjamins, 381-402.

Jackendoff, R. 1997. “Twistin’ the night away”. Language 73: 534-59. 
Jackendoff, R. 2002. "English particle constructions, the lexicon, and the autonomy of syntax”. In Dehé, N., R. Jackendoff, A. McIntyre and S. Urban (Eds.) Verbparticle explorations. Berlin/New York: Mouton de Gruyter, 67-94.

Jackendoff, R. 2010. Meaning and the Lexicon. The Parallel Architecture 1975-2010. Oxford: Oxford University Press.

Konopka, A. and Bock, K. 2009. "Lexical or syntactic control of sentence formulation? Structural generalizations from idiom production”. Cognitive Psychology 58:68-101.

Lakoff, G. 1987. Women, Fire, and Dangerous Things: What Categories Reveal About the Mind. Chicago: University of Chicago Press.

Langacker, R.W. 1987. Foundations of Cognitive Grammar: Theoretical Prerequisites. Standford, CA: Standford University Press.

Laufer, B. and Eliasson, S. 1993. "What causes avoidance in L2 learning: L1-L2 difference, L1-L2 similarity, or L2 complexity?” Studies in Second Language Acquisition 15: 35-48.

Liao, Y. and Fukuya, Y.J. 2004. “Avoidance of phrasal verbs: The case of Chinese learners of English”. Language Learning 54: 193-226.

Lindstromberg, S. 1998. English Prepositions Explained. Amsterdam/Philadelphia: John Benjamins.

Moon, R. 1998. Fixed Expressions and Idioms in English. Oxford: Clarendon Press.

Morgan, P.S. 1997. "Figuring out figure out: Metaphor and the semantics of the English verb-particle construction”. Cognitive Linguistics 8: 327-357.

Navarro, I. 2002. “Towards a description of the meaning of At”. In Cuyckens, H. and G. Radden (Eds.) Perspectives on Prepositions. Tübingen: Max Niemeyer Verlag, 211-230.

O’Dowd, E.M. 1998. Preposition and Particles in English. A Discourse-Functional Account. New York/Oxford: Oxford University Press.

Quirk, R., Greenbaum, S., Leech G. and Svartvik, J. 1985. A Comprehensive Grammar of the English Language London/New York: Longman. 
Rice, S., Sandra, D. and Vanrespaille, M. 1999. "Prepositional semantics and the fragile link between space and time”. In Hiraga, M., C. Sinha and S. Wilcox (Eds.) Cultural, Typological and Psycholinguistic Issues in Cognitive Linguistics. Amsterdam/Philadelphia: John Benjamins, 107-127.

Sandra, D. and Rice, S. 1995. “Network analyses of prepositional meaning: Mirroring whose mind - the linguist's or the language user's?” Cognitive Linguistics 6: 89130.

Schmitt, N. and Carter, R. 2004. "Formulaic sequences in action". In Schmitt, N. (Ed.) Formulaic Sequences. Amsterdam/Philadelphia: John Benjamins, 1-22.

Silvestre, A.J. 2009. Particle Semantics in English Phrasal and Prepositional Verbs: The Case of In and On. Saarbrücken, Germany: VDM Verlag.

Siyanova, A. and Schmitt, N. 2007. "Native and non-native use of multi-word vs. oneword verbs”. IRAL 45: 119-139.

Sjöholm, K. 1995. The Influence of Crosslinguistic, Semantic, and Input Factors on the Acquisition of Phrasal Verbs. Åbo, Finland: Åbo Akademi University Press.

Stefanowitsch, A. and Gries, S. 2003. "Collostructions: investigating the interaction between words and constructions”. International Journal of Corpus Linguistics 8: 209-243.

Svorou, S. 1994. The Grammar of Space. Amsterdam/Philadelphia: John Benjamins.

Tomasello, M. 2000. "Do children have adult syntactic competence”. Cognition. 74: 209-253.

Tomasello, M. 2003. Constructing a Language: A Usage-Based Approach to Child Language Acquisition. Cambridge, MA: Harvard University Press.

Tyler, A. and Evans, V. 2003. The Semantics of English Prepositions. Cambridge: Cambridge University Press.

Vandeloise, C. 1991. Spatial Prepositions: A Case Study from French, Chicago: Chicago University Press.

Vandeloise, C. 1994. "Methodology and analyses of the preposition in". Cognitive Linguistics 5:157-184. 
Verhagen, A. 2007. "Construal and perspectivization". In Geeraerts D. and H. Cuyckens (Eds.) The Oxford Handbook of Cognitive Linguistics. Oxford: Oxford University Press, 48-81.

Waibel, B. 2007. Phrasal verbs in Learner English: A Corpus-Based Study of German and Italian Students. Freiburg, Germany: Albert-Ludwigs-Universität Freiburg.

Wray, A. 2002. Formulaic Language and the Lexicon. Cambridge: Cambridge University Press.

Wulff, S. 2008. Rethinking Idiomaticity: A Usage-based Approach. London/New York: Continuum.

Zlatev, J. 2007. "Spatial semantics”. In Geeraerts, D. and H. Cuyckens (Eds.) The Oxford Handbook of Cognitive Linguistics. Oxford: Oxford University Press, 319350.

\section{Corpora}

BNC, The British National Corpus, version 3 (BNC XML Edition). 2007. Distributed by Oxford University Computing Services on behalf of the BNC Consortium. http://www.natcorp.ox.ac.uk/

ICLE (International Corpus of Learner English) 2002. Centre for English Corpus Linguistics. Université Catholique de Louvain, Belgium

LOCNESS (Louvain Corpus of Native English Essays). Centre for English Corpus Linguistics. Université Catholique de Louvain, Belgium

Received: 26 March 2012

Accepted: 11 May 2012

Cite this article as:

Alejo-González, R. 2012. "Variability in L2 acquisition of formulaic sequences: a study of linguistic factors in the use and learning of phrasal verbs by non-native speakers". Language Value 4 (1), 33-62. Jaume I University ePress: Castelló, Spain. http://www.erevistes.uji.es/languagevalue. DOI: http://dx.doi.org/10.6035/LanguageV.2012.4.3

ISSN 1989-7103

Articles are copyrighted by their respective authors 